\title{
Phenomenal Experience and the Aesthetics of Agency
}

Antonia Peacocke ${ }^{\mathrm{a}}$

${ }^{a}$ Philosophy Department, Stanford University, Stanford, CA, USA

450 Jane Stanford Way

Bldg 90

Stanford, CA 94305

apeacocke@gmail.com 


\title{
Phenomenal Experience and the Aesthetics of Agency
}

\author{
THIS FIELD IS EMPTY
}

Keywords: aesthetics; agency; games; phenomenal experience; C. Thi Nguyen

In his fascinating new book Games: Agency as Art, C. Thi Nguyen claims that games construct and frame forms of human agency in a way that gives rise to a genuine aesthetics of agency.

This is no conceptual engineering on Nguyen's part: Nguyen means to argue that the experiences of agency we have in playing games can be aesthetic experiences in precisely that familiar sense in which any experience at all can be aesthetic. He does come at the point with an already expansive interpretation of the aesthetic, inspired in part by the generosity of John Dewey's (1934) Art as Experience (pp.106-7). But Nguyen also seems to endorse an 'experiential requirement' on the aesthetic: 'we cannot render an aesthetic judgment of a thing without having actually experienced it for ourselves' (p.115). ${ }^{1}$ This is a requirement for an appreciator or judge to have a firsthand phenomenal experience of the object of appreciation or judgment - that is, an experience of the object which feels some way to its subject. Correspondingly, a proper aesthetics of agency relies on the possibility of phenomenal experience of agency itself.

Nguyen has described three forms of harmony (and corresponding disharmonies) that manifest in phenomenal experience of striving gameplay, but his theory can be extended further to capture the aesthetic importance of much more of the rich texture of human agency. I'll argue that certain emotions of agency, certain patterns of attention in action, and the affordances you appreciate in your environment all manifest in phenomenal experience in an aesthetically significant way. I aim here to complement Nguyen's persuasive discussion.

Here's the plan. In Section 1, I'll summarize the relevant portions of Nguyen's book. In Section 2, I'll describe what is needed to show there can be a genuine aesthetics of agency. In Section 3, I'll describe how Nguyen's aesthetics of agency can be significantly extended.

\section{Nguyen's aesthetics of agency}

What a game designer does, according to Nguyen, is to construct and frame a form of agency. This form of agency is one that responds specifically to the constraints and opportunities built into the rules of a game: as he puts it, 'a game designer creates a practical environment;' then 'players adopt the proferred agency, filling it out in various ways' (p.101). In Nguyen's lovely slogan, 'game designers work in the medium of agency' (p.101). The cards of Dixit can be beautifully illustrated, the narrative of Portal can be genuinely funny, and the message of global interdependence in Pandemic can be chilling - but none of these familiar aesthetic features of a physical or virtual game will capture the aesthetics of games per se.

To welcome games into the aesthetic ambit, we need to consider how there can be an aesthetics of agency itself. This is a tall order, but Nguyen does constrain his task: 'I don't mean to imply that aesthetic experiences are essential to art, nor to claim that games' sole purpose is to

\footnotetext{
${ }^{1}$ Cf. Nguyen (2019).
} 
provide aesthetic experiences', he writes. 'Such aesthetic experiences are not unique to games. They often arise in ordinary practical life' (p.101). In this respect, Nguyen picks up a thread from Dewey (1934): experiences in everyday life, outside the cinema and theater and art museum, can be just as aesthetically rich as any experience of art 'proper'. Like Dewey, Nguyen begins with a refreshingly expansive understanding of those experiences that can have (or confer on their objects) genuine aesthetic value. ${ }^{2}$

What Dewey left out, according to Nguyen, is the role of a player in a game. It is one thing to class as aesthetic the spectator's experience of the perfect crack as bat meets baseball; it is another to explain how the batter is having an aesthetic experience of his own swing, one that captures aesthetic qualities that are largely unavailable from the spectator's seat. It's the latter claim Nguyen is concerned to defend in Chapter 5, 'The Aesthetics of Agency'.

There are two ways in which he does that. First, he lays out three different forms of 'practical harmony' that are available for appreciation primarily from the agent's perspective. One is the harmony of solution: the match between practical challenge and its response, which both spectator and player can appreciate. Another is the harmony of action: 'the fit between the obstacle and yourself as the originator of those solutions ... not only how the solution fits the problem, but how [your] decision-making and action-generation were just right to generate that fitting solution' (p.108). Only the agent can experience harmony of action fully, as only the agent is in on the practical reasoning process at all points. The third is the harmony of capacity: that fit between your capacities qua agent and 'the demands of the world' when you fully push yourself to the very limit of your ability (p.109). A 'small whisper of the harmony of capacity may be accessible to spectators; they may have some dim sense of when athletes are near their limits', Nguyen writes (p.110). But its full majesty is only properly available to agents themselves, and only in the context of extremely challenging tasks. Its aesthetic value can help us make sense of why we chase perfect challenges in difficult games.

Second, Nguyen gestures towards a substantive negative aesthetics of agency, one which captures the special value of 'disharmony, unfitness' and so on (p.112). Games that offer experiences of such features are 'equivalent [to] horror movies. They are eloquent and crystallized portraits of ineffectualness. They are horrors of practical incapacity’ (p.113).

Let me repeat that Nguyen is simply not committed to the view that only games offer pleasurable or valuable experiences of these aesthetic qualities. What he does claim is that games are particularly well suited to capture and frame agencies that exhibit these qualities.

In all, the theory Nguyen offers of the aesthetics of agency is conservative: it argues that there can be an aesthetics of agency in just the same sense as there can be an aesthetics of music, or mystery novels, or sculpture. He does not aim to revise the notion of the aesthetic.

What's most relevant for my purposes is that Nguyen cares about respecting what he calls the 'experiential requirement' on aesthetic judgment (p.115). Only those who have themselves enjoyed an experience of some object - have heard the music, or tasted the cake - may judge it aesthetically. The demand is for a phenomenal experience of the relevant object, i.e. one which feels some way to its subject. What matters here is the "phenomenology of aesthetic striving play'; in rock climbing, for example, that might involve 'the feel of the calculations, the intensity of pressure, the explosiveness of the solution' to a challenge (pp.117, 119, emphasis added). Even though you have to take up a second-order reflective attitude to appreciate the aesthetics of

\footnotetext{
${ }^{2}$ There is some disagreement about whether experiences or objects are the primary bearers of aesthetic value. I think objects are. Others working in Dewey's tradition think experiences are. The disagreement won't matter at all for what I want to say here; everything can be adapted to either take on aesthetic value.
} 
that very same agency, the experiential requirement is a demand that you have that basic, unreflective, laser-focused phenomenal experience in the first place.

This experiential requirement, often traced to Kant's aesthetics or to Richard Wollheim's Acquaintance Principle, does face some contemporary dispute. But I agree with it, and since I don't have time to do it justice here, I'll simply assume it for this discussion. ${ }^{3}$ What's more, I agree that it's not only a necessary condition on apt aesthetic judgment; it is also a requirement for aesthetic appreciation more broadly. ${ }^{4}$ So deeply is phenomenal experience intertwined with aesthetics in philosophy that we can treat the experiential requirement as 'an essential marker of the aesthetic', in Nguyen's own words (p.115).

To show how there can be a genuine aesthetics of agency, then, Nguyen must show how the experiential requirement can be met with respect to the agencies framed by games.

\section{The rich texture of agency}

To say what it takes to build up an aesthetics of agency, I'll first need to say a little more about phenomenal experience, and a little more about agency.

To have a phenomenal experience is to feel some way. In Thomas Nagel's (1974) famous phrase, wherever there is phenomenology, there is something it is like to have an experience. Individual aspects of phenomenology are sometimes called 'qualia' (the plural of 'quale').

Paradigm examples of qualia involve bodily sensations and perceptions of properties. A sharp, stabbing pain in your left ear is a quale. The taste of lemon, the sound of a jackhammer, the particular experienced orange of a persimmon are all qualia. There can be more complex or structured qualia - the sound of Etta James's rendition of 'Misty' as a whole is one, and the look of Yayoi Kusama's first pumpkin painting is another. There are also qualia involved in emotions - think of the stab of envy, or the burn of anger - and in imagination and dreams.

Now, your doing pretty much anything will come along with a set of specific feelings. Rolling out dough involves feeling the soft yield of the yeasty mass beneath your rolling pin. Typing up a philosophy paper involves the sounds of a clacking keyboard. Imagining a blue bull and a giant lumberjack traipsing across what is now the US will involve phenomenally significant mental imagery, of hooves pounding dirt and trees falling in forests and so on.

But the fact that doing something comes along with a phenomenal experience simply does not imply that your phenomenal experience is a phenomenal experience of agency itself. In the examples just mentioned, your experience is an experience of dough and pin, or of keyboard sounds, or of the sights and sounds involved in a folk legend. It need not be an experience of your agency in any of these cases, even though rolling dough, typing up a paper, and imagining all tend to be things you do.

To see the difference between a phenomenal experience that always accompanies something in your mind, and a phenomenal experience of that thing, consider an example. I have synesthesia of the grapheme-color variety. Every time I think of the number 3, I have mental imagery of a bright, primary-school green. Often this manifests as a mental image of a numeral

\footnotetext{
${ }^{3}$ Kant (1987); Wollheim (1980). For discussion, see Budd (2003), Hopkins (2011), Livingston (2003), Lord (2016), and Robson (2013).

${ }^{4}$ This itself seems to be something Nguyen endorses. In an earlier paper (2019), he argues that our attempts to judge the aesthetic goodness of items is really just valuable as a way in to appreciation, which itself requires phenomenal experience. This is an earlier discussion of the very same kind of practical inversion Nguyen identifies in gameplay in this book; Nguyen likens the attempt to judge an artwork to a game played for the pleasure of striving towards the win, not for the win itself.
} 
' 3 ' that is inscribed in this green shade (but not always). Despite perfect correlation of this phenomenal experience with my thinking of the number 3 , it is simply not a phenomenal experience of the number 3 (and certainly not of its color). The number 3 is an abstract object. I cannot have a phenomenal experience of any of its properties, because none of them corresponds to any sensation or emotion I might feel.

Your doing something can make a difference to the way some event feels for you, but that still doesn't imply that the difference in phenomenology constitutes a phenomenal experience of your own agency. I don't get nauseated when I'm the one driving, as opposed to being in the passenger seat; my doing something here makes a phenomenological difference for me. But that doesn't mean that my lack of nausea is itself a phenomenal experience of agency.

What could the phenomenology of agency itself involve? To understand that better, consider what it is to exercise agency. We can say a significant amount about it even without wandering too far into the crosshairs of controversies in the philosophy of action. We can say, for instance, that to act is, in part, to cause something to happen, or not to happen, or to keep happening, or to stop happening. ${ }^{5}$ It is to have an effect on the history of the universe, to write your own lines in the book of the world. To act intentionally is in part to exercise control, and exercising control itself involves wielding a yet more robust causal power, one which can surmount certain kinds of obstacles and flex in response to changing circumstances. ${ }^{6}$ Exercising that control usually, if not always, involves paying attention-making use of a limited resource to direct your thoughts and bodily movements towards your end.

Often, but not always, exercising agency requires you to select one option for action among others. This selection might involve significant practical reasoning and deliberation, or it might involve mere dumb 'picking'. Even to start in on this selection process at all, you must in some way appreciate the several opportunities available to you. Exercising your agency, on one token occasion, might begin with appreciating what you could possibly do.

Any discussion of action that leaves out normativity is sorely lacking. A deliberation process culminates (in successful cases) either with a normatively significant commitment to an actioni.e. a decision to act — or an action itself. Deciding and acting both almost always involve responding to reasons, considerations that recommend (or minimally seem to recommend, from your perspective) the relevant action type in your context. In that sense, exercising agency involves a form of valuing: seeing something as worth doing (if not necessarily good).

Last but not least, acting accrues responsibility to you-responsibility not only for what you do intentionally, but also what you do knowingly in doing what you do intentionally. ${ }^{7}$ Not coincidentally, acting also involves normatively significant self-attribution of your actions, at least under certain descriptions. ${ }^{8}$ This self-attribution can ground self-regarding reactive attitudes and other relevant emotions. ${ }^{9}$

That was a very brief description of the rich texture of human agency. With this in mind, I'm struck by the relative flatness of Nguyen's own aesthetics of agency: his practical harmonies (and corresponding disharmonies) capture only a small part of the nature of agency. The harmony of solution is an aesthetic property concerning the relation between problem and

\footnotetext{
${ }^{5}$ Not all philosophers of action agree that actions are constitutively causal; Wittgenstein (1953/2009), Ryle (1949), and Anscombe (1957) all denied that (intentional) actions are picked out by their causes. I'll set this view aside in this paper too.

${ }^{6}$ Cf. Shepherd (2014).

${ }^{7}$ Cf. Bratman (1984).

${ }^{8}$ Anscombe (1957), Hampshire (1963).

${ }^{9}$ Strawson (1962).
} 
solution; the harmony of action is an aesthetic property concerning the relation between problem and the way the solution is chosen; and the harmony of capacity is an aesthetic property concerning the relation between one's (causal, active) capacities and what one actually does. But there is much more to agency than those three relations alone.

I don't think Nguyen meant for these harmonies (and their corresponding disharmonies) to constitute the entirety of the aesthetics of agency. For that reason, my task in the remainder of this paper is entirely friendly to his view. I'll suggest three ways to fill out an aesthetics of agency, so that it can capture and respect the full rich texture of human agency.

\section{Three extensions of Nguyen's view}

I'll argue that the aesthetics of agency can incorporate three elements Nguyen left out: emotions of agency, patterns of attention, and affordances.

\subsection{Emotions of agency}

Let's start with an entirely discredited proposal from William James.

In his 1904 President's Address to the American Psychological Association, William James (1905) laid out a theory of what agency, or what he called 'activity', in these terms:

[an agent] feels the push, the obstacle, the will, the strain, the triumph or the passive giving up, just as he feels the time, the space, the swiftness or intensity, the movement, the weight and color, the pain and pleasure, the complexity, or whatever remaining characters the situation may involve ... The word 'activity' has no content save these experiences of process, obstruction, striving, strain, or release, ultimate qualia as they are of the life given us to be known. (p.6)

What acting really consists in, James thought, was such qualia. The view is an expression of James's unbending commitment to 'radical empiricism', and in particular his 'principle of pure experience': 'Nothing shall be admitted as fact, it says, except what can be experienced at some definite time by some experient' (3). This commitment led James, in the face of skepticism about agency, to defend its existence with some phenomenology of agency.

As a metaphysical view about the nature of agency, the view simply cannot be right. Acting cannot just be a matter of feeling some way; that's not consistent with the fact that acting involves exercising causal powers, having an effect on the world. ${ }^{10}$ But James's lovely portrayal of the phenomenology of agency can be considered apart from its metaphysical commitments. We can use his descriptions as starting points for our first extension of Nguyen's aesthetics of agency. Part of what James offers is a take on the emotions of agency.

Let's take 'triumph' first. To triumph is to succeed, and depending on the context, that triumph can be constituted by all sorts of events taking place in the world. To triumph is also to do something. Triumph is inseparable from agency; a stroke of good luck that gets you what you've so long chased is not a triumph. Most importantly for our purposes, though, triumph has

\footnotetext{
${ }^{10}$ I assume here that the exercise of a causal power cannot just be a matter of feeling. Once again I set aside those views on which action isn't really a causal matter at all. But note that even Anscombe (1957) would reject this view: a teleological metaphysics of action (on which intentional action is something to which a request for normative reasons can apply) cannot just reduce to a matter of qualia either.
} 
emotional significance. The emotional dynamics of triumph are captured beautifully in the last movement of Beethoven's famous Fifth Symphony.

James's 'passive giving up' has just as much emotional resonance. There are genuine feelings of resignation of an attempt. They might feel like deflation. They might blend relief and depressive melancholy. These are well exemplified in the brooding minor turns of Chopin's Grand Valse Brillante (Op. 34, No. 2), when one main theme transforms into a hollow, flattened version of itself.

Consider next that 'effort, strain or squeeze' James describes (p.6). These terms can describe literal sensations in musculature, but they can also (perhaps metaphorically) describe emotional engagement in a practical situation. Effort need not be muscular: consider the intense feeling of effort involved in trying to stay awake in a tedious lecture. You can strain and squeeze in marshalling all your cognitive efforts towards calculating a solution to an abstract problem, like a question set on a difficult examination.

There are a couple things to note about these emotions of triumph, resignation, and effort. The first thing to note is that all three distinctively involve agency: you respond to yourself as agent when you feel triumph, resignation, or effort. The second thing to note is that all three are undeniably phenomenal. As emotions, they feel some way.

These are just examples of emotions of agency; there are many more. A certain type of pride, a certain type of shame, and a certain type of determination all relate distinctively to what you are doing or have done, and all these emotions have distinctive phenomenology.

It is easy - at least for a player like me - to see how these emotions of agency can arise in the context of gameplay, even gameplay engaged purely for the aesthetic value of striving. Nor should it be difficult to see why these emotions, as any emotions, can partially ground the aesthetic value of gameplay, either in positive or negative (horror-movie) mode. An experience's being nail-biting, anxiety-ridden, and torturous would certainly be relevant to aesthetic value; so would its being triumphant, reassuring, rewarding of the pains of effort.

These emotions can partly constitute a phenomenal experience that has (or reflects) real aesthetic value. Even if James's metaphysics of agency isn't worth retaining, his phenomenology of the emotions of agency is invaluable in itself.

\subsection{Patterns of attention}

Two further famous passages in James, this time from his Principles of Psychology (1890), will introduce this next extension to Nguyen's aesthetics of agency.

My experience is what I agree to attend to. Only those items which I notice shape my mind without selective interest, experience is an utter chaos. Interest alone gives accent and emphasis, light and shade, background and foreground - intelligible perspective, in a word. (p. 403, emphasis original)

Every one knows what attention is. It is the taking possession by the mind, in clear and vivid form, of one out of what seem several simultaneously possible objects or trains of thought. Focalization, concentration, of consciousness are of its essence. It implies withdrawal from some things in order to deal effectively with others, and is a condition which has a real opposite in the confused, dazed, scatterbrained state which in French is called distraction, and Zerstreutheit in German. (p.403-4) 
Attention, James notes here, is a modification of phenomenal experience. Any phenomenal experience has a 'foreground' and a 'background', with what is attended in the foreground. What you attend to makes a phenomenological difference to your experience.

There are two ways attention is wrapped up in agency. Attending is itself something you do, as James notes, and as Sebastian Watzl (2017) has recently argued. But attending in a particular way is also something you really must do to exercise your agency in any way at all. ${ }^{11}$

Consider, as an example, the patterns of attention implicated in returning a serve in tennis. To perform this action, you'll need to attend to the particular angle of your opponent's racquet as it meets the ball, and also to attend to the ball as it flies off their strings. You'll need to attentively adjust your own racquet angle in response, and choose a direction of strike in order to return the serve successfully into their side of the court. Just as there are patterns of attention required for you to engage in this action, there are also certain kinds of attention that would be inappropriate or even perhaps inconsistent with returning your opponent's serve. It won't do to attend to the birds flying overhead, or the color of your own shoes. Your acting in this way, then, entirely structures your phenomenological experience by bringing certain things and features into the foreground, and pushing others into the background.

Nguyen is perfectly well aware of the patterns of immersion involved in striving gameplay; I don't think there's anything I'm expressing here that he would reject, or find surprising. What he does not explicitly note, though, is that this very patterning of attention is itself a phenomenologically meaningful feature of experience, and thus it can partially constitute an aesthetic experience of gameplay. Even better: as something that you $d o$, and additionally as something that you must do in order to do other things, attending is a feature of agency.

Any complete aesthetics of agency can give pride of place to attention and the way that it structures phenomenal experience. The foreground/background structure of phenomenal experience is as much a part of phenomenology of gameplay as individual qualia. And the structure of your attention is just as relevant to the aesthetic value that an experience has (or reflects) as those qualia themselves.

\subsection{Affordances}

Nguyen highlights the importance of decision-making processes in his discussion of the practical harmony of action. But another aspect of an agent's experience before decision-making has phenomenological importance. This is the phenomenologically salient, sometimes perceptual appreciation of opportunities for action, or what J.J. Gibson (1979) famously called 'affordances'.

When you stand in your kitchen and look at the scene around you, your experience will represent all sorts of stable features of the environment: the color of your countertops, the shape of your plates, and so on. But it will also represent various ways in which the items around you afford particular, familiar actions. The stove knobs afford turning; the spatulas afford flipping; the fridge door affords opening; that apple affords a juicy bite. The way your experience feels is partly structured by your appreciation of these opportunities. Such affordances interact significantly with the phenomenal relevance of attention: the clear affordances offered by thick

\footnotetext{
${ }^{11}$ Compare Ryle (1949) on intelligent action.
} 
slices of chocolate cake can be genuinely distracting, and keep you from paying full attention to the paper you have open on your laptop. ${ }^{12}$

This is not to say that all affordances demand immediate attention. Those that are particularly compelling, and conflict directly with your current task, can be distracting. But affordances can also structure a lack of attention to features of your environment. As Heidegger (1962) famously noted, tools in good working order fade into the background of your phenomenology as you use them; these 'ready-to-hand' items are felt practically as extensions of your own body, with all the fluidity that involves. But when a tool breaks, and its affordances fade from your phenomenal experience, its other features - perhaps its flimsy plastic construction, its suddenly noticeably worn coloring - jump into the foreground of your experience again. As discussed in the previous section, these attentional modifications are themselves modifications of your phenomenal experience. And they are directly related to your own agency_in particular, your appreciation of what actions are available to you.

Gameplay, whether striving or not, develops these phenomenal experiences of affordances and modifies how other opportunities for action appear (or don't appear) to us. It might be less obvious that this aspect of phenomenology is aesthetically relevant, but there is significant precedent for the aesthetic relevance of affordances outside of the aesthetics of games. Consider the interactive installations of the celebrated artist Felix González-Torres, such as his series of endlessly replenished piles of candies, which museumgoers are encouraged to pick up and eat. The aesthetics of these works center around the fraught interplay a viewer might feel between respectful, awkward reticence and the childlike excitement of bodily engagement, of touching and tasting and ultimately consuming a constitutive part of an installation. This interplay becomes more emotionally and politically meaningful when the size of the installation is matched to the bodyweight of the artist's lover who died of AIDS, as in Untitled (Portrait of Ross in L.A.), from 1991.

This example, from outside the world of games, merely illustrates a point we could make more generally for games: they offer rich aesthetic experiences in part due to the phenomenology involved in appreciating opportunities for action, or affordances. Affordances belong in a fully developed aesthetics of agency, just as emotions of agency and patterns of attention do.

\section{Conclusion}

Nguyen's striking suggestion that agency itself can have a substantive aesthetics is an important one. The case he makes for this conclusion is already persuasive. What I hope to have done in this paper is show how fertile his suggestion is, simply by extending it to deepen the aesthetics of agency in a way that responds to the rich texture of our agency. But I have certainly not been exhaustive here either. I hope that Nguyen's book represents just the start of an exciting research program in the aesthetics of agency.

\footnotetext{
${ }^{12}$ One of my favorite illustration of the distractions of affordances is in a cartoon by Liana Finck: https://condenaststore.com/featured/alice-in-responsibilityland-liana-finck.html
} 


\section{References}

Anscombe, G.E.M. (1957). Intention. Oxford: Basil Blackwell.

Bratman, Michael (1984). 'Two faces of intention.' Philosophical Review 93(3): 375-405.

Budd, Malcolm (2003). 'The acquaintance principle.' British Journal of Aesthetics 43.4: 386392.

Dewey, John (1934). Art as Experience. New York: Perigee Books.

Gibson, J.J. (1979). The Ecological Approach to Visual Perception. New York: Houghton Mifflin.

Hampshire, Stuart (1959). Thought and Action. New York: The Viking Press.

Heidegger, Martin (1962). Being and Time. Trans. John Macquarrie and Edward Robinson. New York: Harper \& Row.

Hopkins, Robert (2011). 'How to be a pessimist about aesthetic testimony.' Journal of Philosophy 108.3: 138-157.

James, William (1890). The Principles of Psychology, Volume One. New York: Dover.

James, William (1905). 'The experience of activity.' The Psychological Review XII(1): 1-17.

Kant, Immanuel (1987). Critique of Judgment. Trans. Werner S. Pluhar. Indianapolis: Hackett.

Livingston, Paisley (2003). 'On an apparent truism in aesthetics.' British Journal of Aesthetics 43.3, 260- 278.

Lord, Errol (2016). 'On the rational power of aesthetic testimony.' British Journal of Aesthetics 56.1: $1-13$.

Nagel, Thomas (1974). 'What is it like to be a bat?' Philosophical Review 83: 435-50.

Nguyen, C. Thi (2020). Games: Agency as Art. NYC: Oxford University Press.

Robson, Jon (2013). 'Appreciating the acquaintance principle: A reply to Konigsberg.' British Journal of Aesthetics 53.2: 237-245.

Ryle, Gilbert (1949). The Concept of Mind. Chicago: University of Chicago Press.

Shepherd, Joshua (2014). 'The contours of control.' Philosophical Studies 170(3): 395-411.

Strawson, P.F. (1962). 'Freedom and resentment.' Proceedings of the British Academy 48: 1-25.

Wittgenstein, Ludwig (1953/2009). Philosophical Investigations. 4th ed. Trans. G.E.M.

Anscombe, P.M.S. Hacker, and Joachim Schulte. Oxford: Blackwell.

Wollheim, Richard (1980). Art and Its Objects. $2^{\text {nd }}$ ed. Cambridge: Cambridge University Press. 